\title{
Extended O-GIcNAc on HLA Class-I-Bound Peptides
}

\author{
Fabio Marino, ${ }^{\dagger, \downarrow}, \nabla$ Marshall Bern, ${ }^{*},{ }^{\S, \nabla}$ Geert P. M. Mommen, ${ }^{\dagger, \uparrow, \|}$ Aneika C. Leney, ${ }^{\dagger, \dagger}$
} Jacqueline A. M. van Gaans-van den Brink, ${ }^{\perp}$ Alexandre M. J. J. Bonvin, ${ }^{\#}$ Christopher Becker, ${ }^{\S}$ Cécile A. C. M. van Els, ${ }^{\perp}$ and Albert J. R. Heck ${ }^{*},+$,

\author{
${ }^{\dagger}$ Biomolecular Mass Spectrometry and Proteomics, Bijvoet Center for Biomolecular Research and Utrecht Institute for \\ Pharmaceutical Sciences, ${ }^{\ddagger}$ Netherlands Proteomics Centre, and ${ }^{\#}$ Computational Structural Biology, Bijvoet Center for Biomolecular \\ Research, Utrecht University, Padualaan 8, 3584 CH Utrecht, The Netherlands \\ ${ }^{\S}$ Protein Metrics Inc., San Carlos, California 94070, United States \\ "Institute for Translational Vaccinology, 3721 MA Bilthoven, Netherlands \\ ${ }^{\perp}$ Centre for Infectious Disease Control, National Institute for Public Health and the Environment, 3721 MA Bilthoven, The \\ Netherlands
}

\section{Supporting Information}

ABSTRACT: We report unexpected mass spectrometric observations of glycosylated human leukocyte antigen (HLA) class I-bound peptides. Complemented by molecular modeling, in vitro enzymatic assays, and oxonium ion patterns, we propose that the observed $\mathrm{O}$ linked glycans carrying up to five monosaccharides are extended O-GlcNAc's rather than GalNAc-initiated Oglycans. A cytosolic O-GlcNAc modification is normally terminal and does not extend to produce a polysaccharide, but O-GlcNAc on an HLA peptide presents a special case because the loaded HLA class I complex traffics through the endoplasmic reticulum and Golgi apparatus on its way to the cell membrane and is hence exposed to glycosyltransferases. We also report for the first time natural HLA class I presentation of $\mathrm{O}$ - and $\mathrm{N}$-linked glycopeptides derived from membrane proteins. HLA class I peptides with centrally located oligosaccharides have been shown to be immunogenic and may thus be important targets for immune surveillance.

$\mathrm{I}_{\mathrm{d} e \mathrm{~m}}$ dentification of peptide antigens presented by human leukocyte antigen (HLA) class I molecules is of great importance for the development of vaccines and immunotherapies, ${ }^{1}$ including breakthrough T-cell therapies. ${ }^{2}$ Along with peptide sequence and protein of origin, it is also important to identify posttranslational modifications (PTMs), because alteration of PTMs is a recognized hallmark of many diseases, including cancer and autoimmune diseases, and altered PTMs can strongly regulate immune system recognition of HLA class I peptides. A small fraction of the HLA class I peptides have been reported to carry phosphorylation ${ }^{3}$ or O-GlcNAcylation, ${ }^{4}$ indicating that these regulatory modifications pass intact through processing and presentation events in antigen presenting cells. O-GlcNAc is a dynamic PTM that occurs in the cytosol, ${ }^{5}$ so OGlcNAc-ylated proteins may degrade through a route involving the proteasome and classical HLA class I loading. ${ }^{6}$ Membrane glycoproteins may also contribute HLA class I peptides via cross- presentation, ${ }^{7}$ but HLA class I peptides carrying extracellular Oor N-linked glycosylation have not been previously observed.

Here we report a variety of glycosylated HLA class I peptides presented by the HLA-A, -B, and -C heterozygous Blymphoblastoid cell line GR. The most surprising observations are of O-linked glycans with up to five monosaccharides on serines and threonines in nuclear and cytosolic proteins (Table 1). Based on LC-MS/MS analysis using indicative intensity pattern of the fragment ions, in vitro enzymatic assays, existing literature, the glycopeptide sequences, and the subcellular localization of the proteins of origin, we explicitly assign these O-linked glycans as primarily O-GlcNAc, along with extensions by Gal, Gal-NeuAc, and further monosaccharides.

Figure 1 shows illustrative annotated mass spectra of HLA class I glycopeptides, acquired on an Orbitrap Fusion instrument (Thermo Fisher Scientific) with high-mass accuracy and high resolution. We used a rather novel fragmentation mode denoted EThcD, ${ }^{8}$ which employs both electron-transfer dissociation and higher-energy (beam-type) collisional dissociation. ${ }^{9,10}$ EThcD spectra include c- and z-ions with labile modifications intact for confident modification site localization ${ }^{9}$ as well as oxonium ions from glycan fragments for glycopeptide validation. As indicated, the $c 3-c 9$ ions enabled unambiguous localization of the glycan, while the oxonium ions at 204 and $274 \mathrm{Da}$, the O-GlcNAc diagnostic oxonium ion fragmentation pattern (see Supporting Information (SI)), ${ }^{11}$ and neutral losses of the HexNAc acetyl group and the labile sialic acid NeuAc corroborate the exact monosaccharide composition (see also SI). All spectrum assignments were made using Byonic software, ${ }^{12}$ which includes special support for glycopeptide identification. The protein of origin for the peptide in Figure 1 is the Zinc finger protein 281. Uniprot lists this protein as localized in the nucleus, ruling out GalNAc-initiated O-glycosylation, which is thought to be exclusively extracellular, either on extracellular parts of membrane proteins or on secreted proteins.

Figure 2 shows an EThcD spectrum of a HLA class I glycopeptide from the RNA-binding protein 27 carrying

Received: June 25, 2015

Published: August 17, 2015 
Table 1. Detected HLA Class 1 Glycopeptides Containing Extended O-GlcNAc Moieties

\begin{tabular}{|c|c|c|c|c|c|}
\hline $\begin{array}{l}\text { peptide: } \mathrm{g}=\text { glyco, } \mathrm{p}= \\
\text { phospho, } \mathrm{d}=\text { dimethyl }\end{array}$ & $\begin{array}{c}\text { glycan masses: } 0=\text { unmodified, } 203= \\
\text { HexNAc, } 162=\text { Hex, } 291=\text { NeuAc }\end{array}$ & protein name (gene) & $\begin{array}{l}\text { HLA } \\
\text { allele }\end{array}$ & $\begin{array}{l}\text { predicted affinity } \\
\quad\left(\mathrm{IC}_{50}, \mathrm{~nm}\right)\end{array}$ & $\begin{array}{l}\text { YinOYang } \\
\text { score }\end{array}$ \\
\hline LPKPANgTSAL & 365 & DNA-binding protein RFX7 (RFX7) & $\mathrm{B}^{*} 07: 02$ & 17 & 0.73 \\
\hline RPPVgTKASSF & 203,656 & $\begin{array}{l}\text { R3H domain-containing protein } 2 \\
\text { (R3HD2) }\end{array}$ & $\mathrm{B}^{*} 07: 02$ & 27 & 0.82 \\
\hline RVKpTPTgSQSY & $0,203,365,730,1021$ & zinc finger protein $281(\mathrm{ZN} 281)$ & $A * 03: 01$ & 284 & 0.70 \\
\hline RVKpTPTgSQSYR & $0,203,365,656,730,1021$ & zinc finger protein $281(\mathrm{ZN} 281)$ & $\mathrm{A}^{*} 03: 01$ & 445 & 0.70 \\
\hline APVgSPSSQKL & 656 & $\begin{array}{l}\text { telomeric repeat-binding factor 2- } \\
\text { interacting protein } 1 \text { (TE2IP) }\end{array}$ & $\mathrm{B} * 07: 02$ & 70 & 0.58 \\
\hline IPdRPPIgTQSSL & $203,365,656,730,1021$ & RNA-binding protein 27 (RBM27) & $\mathrm{B}^{*} 07: 02$ & 9 & 0.68 \\
\hline
\end{tabular}

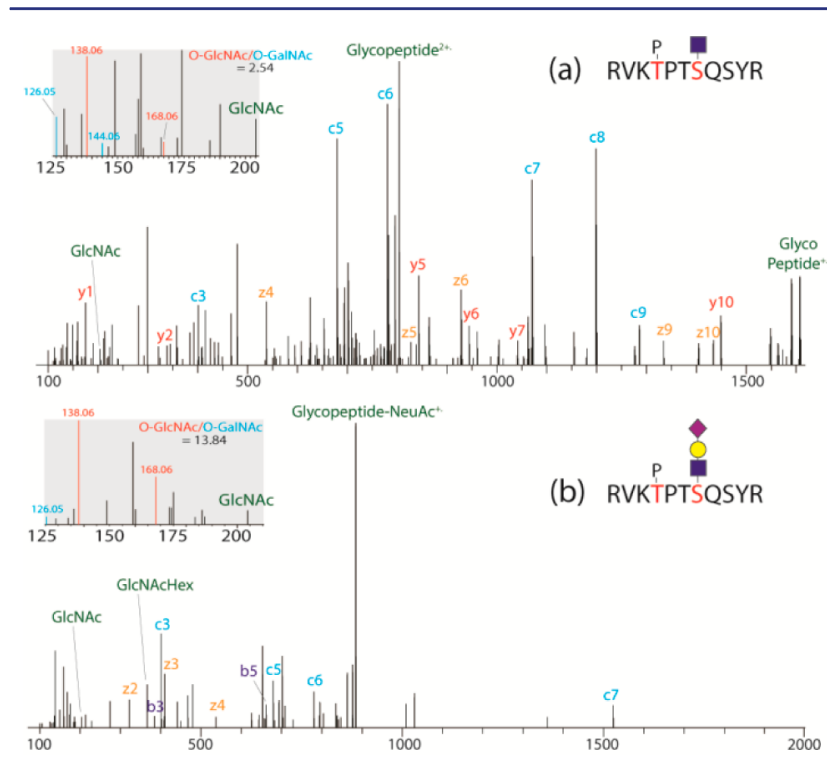

Figure 1. EThcD spectra of two forms of an HLA class I glycopeptide derived from ZN281, a known nuclear protein, carrying (a) GlcNAc (203 Da) and (b) GlcNAc(1)Hex(1)NeuAc(1) (656 Da) O-linked to $\mathrm{Thr}^{345}$. To decipher the saccharide identity of the O-linked saccharide moiety, the ratio of the abundance of the $(\mathrm{m} / z 138+\mathrm{m} / z 168)$ to $(\mathrm{m} / \mathrm{z}$ $126+m / z 144)$ oxonium ions is taken. Ratio values $>1$ indicate an OGlcNAc core, whereas values $<1$ indicate an O-GalNAc core. ${ }^{11}$ The inset shows the prevalence for the diagnostic O-GlcNAc fragment ions.

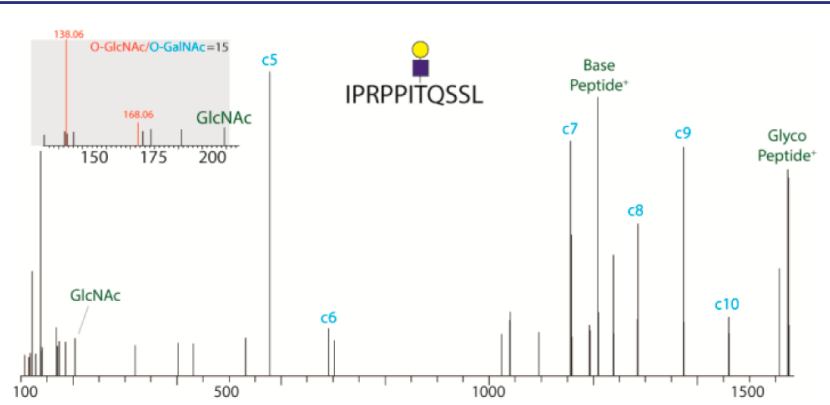

Figure 2. EThcD spectrum of an HLA class I glycopeptide derived from the RNA-binding protein 27, a known O-GlcNAc-ylated protein. Annotation of $\mathrm{c5}-\mathrm{c} 10$ ions enabled the exact localization of $\operatorname{GlcNAc}(1) \operatorname{Hex}(1)(365 \mathrm{Da})$ on $\mathrm{Thr}^{386}$. The insert highlights the fragment ions diagnostic of an O-GlcNAc core.

$\operatorname{HexNAc}(1) \operatorname{Hex}(1)$. This protein has previously been reported to be O-GlcNAcylated. ${ }^{13,14}$ At the ASMS 2014, Hunt et al. from the University of Virginia showed the 9-residue glycopeptide RPPIT(+HexNAc)QSSL, with and without methylation on the $\mathrm{N}$-terminal Arg, as an O-GlcNAcylated HLA class I peptide and a possible marker for acute lymphoblastic leukemia cells. We observe the 11-residue, IPRPPITQSSL peptide, with and

without arginine (di)methylation, with five different glycans located at the same threonine: $\operatorname{HexNAc}, \operatorname{HexNAc}(1) \operatorname{Hex}(1)$, $\operatorname{HexNAc}(1) \operatorname{Hex}(1) \mathrm{NeuAc}(1), \operatorname{HexNAc}(2) \operatorname{Hex}(2)$, and $\operatorname{HexNAc}(2) \mathrm{Hex}(2) \mathrm{NeuAc}(1)$.

Based on the relative intensities of the diagnostic ions specific to O-GlcNAc (GlcNAc/GalNAc ratio) (Figures S1-2, Tables S3-4), ${ }^{11}$ we reason that the observed glycopeptides have an OGlcNAc "core" which is extended by Gal, optionally extended by $N$-acetyl lactosamine, and optionally capped by NeuAc ( $N$-acetyl neuraminic acid), as these are the most usual elongations of antennal GlcNAc in human. Figure 3 illustrates our hypothesis

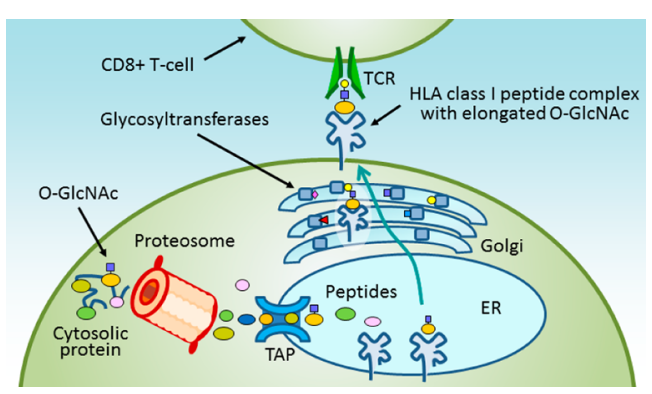

Figure 3. Elongation of O-GlcNAc's on HLA class I glycopeptides. Cytosolic proteins carrying O-GlcNAc are degraded in the immune proteasome, leaving the O-GlcNAc intact. Glycopeptides are translocated via the transporter associated with antigen presentation into the ER and loaded onto HLA class I molecules. The loaded glycopeptide travels through the Golgi, where the O-GlcNAc is elongated by glycosyltransferases, on the way to the plasma membrane for presentation to the TCR on CD8+ T cells.

regarding the formation of these modifications on HLA class Ibound peptides using the classical class I antigen presentation pathway. ${ }^{6}$ O-GlcNAc starts on a cytosolic protein, survives degradation by the proteasome and translocation into the endoplasmic reticulum (ER), and is then loaded onto an HLA class I molecule and extended by glycosyltransferases, starting with $\beta 1,4$ galactosyltransferase, in the Golgi. Galactosyltransferase extension is a standard method to detect O-GlcNAc, ${ }^{15}$ and single N-linked GlcNAc's in the ER of engineered cells almost uniformly elongate to GlcNAc-Gal-NeuAc in the Golgi. ${ }^{5}$ To our knowledge, the findings reported here are the first observations of O-linked GlcNAc extended in vivo.

In total we observed 18 HLA class I-peptides carrying extended HexNAc moieties and identified 14 other glycopeptides having a nonextended HexNac (Table S1). For 28 of the 32, we interpret the O-linked saccharide as O-GlcNAc, based on the diagnostic fragment ions ratio, protein subcellular localization, and previously identified O-GlcNAc proteins and modification sites in the dbOGap. ${ }^{13}$ The 14 O-GlcNAc-ylated source proteins reside in the nucleus and/or cytosol and are involved in DNA or 
RNA binding and other functions. Seven of the 14 source proteins have been previously reported as carrying O-GlcNAc, four at the identical sites observed here. Figures S5-S42 show all 32 unique O-GlcNAc-ylated glycopeptides, including 28 unique peptide forms and 14 non-extended O-GlcNAc's, out of $\sim 15,000$ unique HLA class I peptides in the entire data set, in agreement with earlier estimates that O-GlcNAc-ylation constitutes the bulk of glycosylation on HLA class I peptides and appears on roughly $0.1 \%$ of these peptides. ${ }^{4,16}$ Interestingly, of the 14 O-GlcNAcylated peptides observed, all rank highly by the YingOYang computational O-GlcNAc predictor. ${ }^{17}$ Enzymatic in vitro OGlcNAcylation studies using synthetic peptide analogues confirmed that all nine probed peptides could be O-GlcNAcylated by the O-GlcNAc transferase (Figure S2, Table S4). We also identified 2 O-GalNAc-ylated peptides, one extended and the other non-extended. Indeed, these synthetic peptides analogues did not undergo O-GlcNAcylation in vitro (Figures S3-S4, Table S4).

The peptides RVKpTPTgSQSY and RVKpTPTgSQSYR of ZNF218 were detected with both a phosphorylated $\mathrm{Thr}^{886}$ and an (extended) O-GlcNAc on $\mathrm{Ser}^{891}$. Both modification sites have been reported previously, albeit not as co-occurring. ${ }^{14,18}$ The proximity of O-GlcNAc-ylation with arginine methylation and dimethylation in IPRPPITQSSL and phosphorylation in RVKTPTSQSY hints at potential PTM crosstalk. ${ }^{19}$

The mono- or oligo O-GlcNAc moieties were found exclusively at the peptides' center residues (P3-P7), with a preference for P5 ( 7 out of 15 glycosylation sites). As opposed to the previously reported set of unmodified peptides, ${ }^{8}$ a significant preference $\left(p\right.$-value $\left.<10^{-5}\right)$ was found for the full set of glycopeptides to be bound to the HLA-B*07 allele ( 15 out of 16), rather than to any of the other alleles present in the GR lymphoblastoid cell line. Upon further inspection of the $\mathrm{O}$ GlcNAc-ylated peptide sequences, there is resemblance to motifs recognized by various kinases ${ }^{5}$ and preference for nearby proline residues ${ }^{20}$ especially at the -2 and -3 positions, so the common proline anchor at position P2 in HLA-B*07-presented peptides may lead to a preference for peptides with central O-GlcNAcylation. Indeed, proline at the -3 position is consistent with the consensus sequence for O-GlcNAc, ${ }^{17}$ giving additional evidence for an O-GlcNAc core saccharide over the alternative O-GalNAc core whereby proline is typically found at the -1 position. ${ }^{21}$

Starting from a crystal structure ${ }^{22}$ of a HLA-B*07-peptide complex (3VCL), we modeled the HLA-B*07 molecule complexed to GlcNAc-ylated RPPVTKASSF using the information-driven docking program $\mathrm{HADDOCK}^{23} \mathrm{We}$ observed that the modified threonine is solvent exposed and not directly involved in binding to the HLA class I molecule groove (Figure 4 and Table S2), which suggests that an O-GlcNAc at this site would be accessible to glycosyltransferases in the Golgi apparatus. Similar modeling observations were made for other glycosylated peptides (see Table S2). In our hypothesis, the glycosyltransferases would remain active in the HLA binding cleft environment.

Along with the 24 unique HLA class I O-GlcNAc-ylated peptide forms, Table S1 lists three peptides carrying what we interpret to be O-GalNAc and another peptide with a small $\mathrm{N}$ linked oligosaccharide. Even though these glycopeptides are just single examples, each represents an unusual observation.

The glycopeptide PSSGLGV(+HexNAc)TKQDLGPVPM is derived from the Golgi/membrane-associated HLA class II histocompatibility antigen invariant chain and is thus more likely to carry O-GalNAc than O-GlcNAc. Processing and presentation

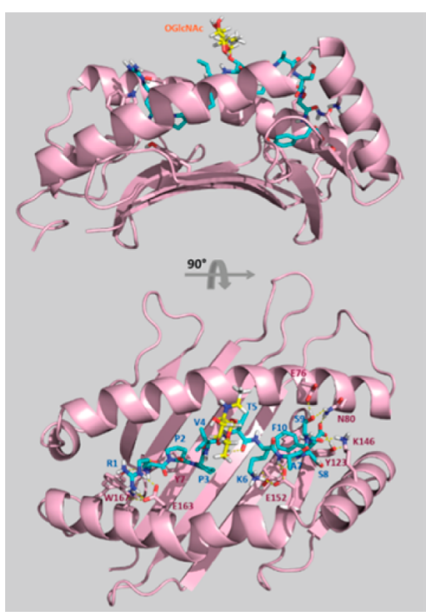

Figure 4. HADDOCK ${ }^{23}$ model of HLA-B*07 complexed with RPPVT(+GlcNAc)KASSF. GlcNAc (yellow) is surface exposed and likely to be accessible to glycosyltransferases in the Golgi.

of extracellular O-glycosylation have been extensively studied for the tumor-associated mucin MUC1 in in vitro models and clinical studies, but these studies ${ }^{24,25}$ have not identified naturally occurring mucin-type HLA class I peptides. Membrane glycoproteins can recycle in endolysosomal compartments from which they may gain access to the classical HLA class I pathway through escape into the cytosol; this is a known crosspresentation route. ${ }^{7}$ Alternatively, processing of membrane proteins without glycan removal can likely occur in the endolysosomal compartment, already evidenced in dendritic cells by the detection of MUC1 glycosylated peptides ${ }^{26}$ presented by I-Ab molecules, the murine counterpart of HLA class II. A fraction of cell surface HLA-class I molecules recycles through the endolysosomal compartment where reloading with peptidic cargo may occur. ${ }^{27}$

Finally, the glycopeptide KPAPPFgNVTV is derived from the membrane-associated Interleukin-21 receptor, modified at $\operatorname{Asn}^{125}$ (Table S1). The glycan is $\operatorname{HexNAc}(1) \operatorname{Hex}(1) \operatorname{Fuc}(1)$, which we interpret to be fucosylated core, a common N-glycan truncation, extended in the Golgi by $\beta 1,4$ galactosyltransferase. It is known that $\mathrm{N}$-glycosylated proteins can enter the classical HLA class I loading route by retrograde transport from the ER into the cytosol, a pathway for degradation of misfolded glycoproteins. This process however is linked to the activity of cytosolic peptide-N-glycanase, cleaving between Asn and the core and deamidating the asparagine. Deamidated asparagines are regularly found on HLA class I peptides, ${ }^{28}$ including in our data set. ${ }^{8}$ It is possible that the glycanase failed to remove the truncated $\mathrm{N}$-glycan, or alternatively, the peptide with a truncated $\mathrm{N}$-glycan trafficked to the ER from the endolysosome. N-glycans can survive glycanase activity in the endolysosomal environment, as $\mathrm{N}$-glycopeptides presented by HLA class II molecules have been observed. ${ }^{29}$

The glycans described here are likely to affect immune recognition. In mice it has been reported that adding centrally located oligosaccharides to the murine $\mathrm{H}-2 \mathrm{D}^{\mathrm{b}}$ class I peptides can increase their immunogenicity. ${ }^{30}$ Other structurally unusual HLA class I peptides, such as long viral peptides, centrally bulging from the HLA class I binding groove due to their noncanonical lengths, are able to engage TCRs and induce immunodominant responses. $^{31-33}$ Thus, the extended-O-GlcNAc HLA class I peptides found in this study may constitute a functional category 
of $\mathrm{T}$ cell epitopes and play a role in sensing metabolic processes regulated by O-GlcNAc-ylation, including processes that may be dysregulated in diseases such as cancer and diabetes. ${ }^{34}$

\section{ASSOCIATED CONTENT}

\section{S Supporting Information}

The Supporting Information is available free of charge on the ACS Publications website at DOI: 10.1021/jacs.5b06586.

Experimental details and data (PDF)

\section{AUTHOR INFORMATION}

\section{Corresponding Authors}

*bern@proteinmetrics.com

*a.j.r.heck@uu.nl

\section{Author Contributions}

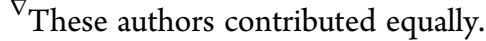

\section{Notes}

The authors declare no competing financial interest.

\section{ACKNOWLEDGMENTS}

We kindly acknowledge Dr. H. Meiring (IntraVacc, Bilthoven) for SCX fractionation, and the laboratory of Dr. H. Ovaa (Nederlands Kanker Instituut) for providing the synthetic analogues and the O-GlcNAc transferase. This work was supported by the project Proteins At Work (project 184.032.201), a program of The Netherlands Proteomics Centre financed by The Netherlands Organization for Scientific Research (NWO) as part of the National Roadmap Large-scale Research Facilities of The Netherlands and by the projects Immunoproteomics and Correlates of Protection, financed by the Dutch Government. Protein Metrics gratefully acknowledges support from NIH grants GM100634 and GM103362. This work was also supported by the Institute for Chemical Immunology, an NWO Gravitation project funded by the Ministry of Education, Culture, and Science of The Netherlands.

\section{REFERENCES}

(1) Parmiani, G.; Castelli, C.; Dalerba, P.; Mortarini, R.; Rivoltini, L.; Marincola, F. M.; Anichini, A. J. Natl. Cancer Inst. 2002, 94 (11), 805818.

(2) Couzin-Frankel, J. Science 2013, 342 (6165), 1432-1433.

(3) Cobbold, M.; De La Peña, H.; Norris, A.; Polefrone, J. M.; Qian, J.; English, A. M.; Cummings, K. L.; Penny, S.; Turner, J. E.; Cottine, J.; Abelin, J. G.; Malaker, S. A.; Zarling, A. L.; Huang, H.-W.; Goodyear, O.; Freeman, S. D.; Shabanowitz, J.; Pratt, G.; Craddock, C.; Williams, M. E.; Hunt, D. F.; Engelhard, V. H. Sci. Transl. Med. 2013, 5 (203), 203ra125.

(4) Haurum, J. S.; Høier, I. B.; Arsequell, G.; Neisig, A.; Valencia, G.; Zeuthen, J.; Neefjes, J.; Elliott, T. J. Exp. Med. 1999, 190 (1), 145-150.

(5) Hart, G. W.; Akimoto, Y. Essentials of Glycobiology; Cold Spring Harbor Laboratory Press: New York, 2009.

(6) Yewdell, J. W.; Reits, E.; Neefjes, J. Nat. Rev. Immunol. 2003, 3 (12), 952-961.

(7) Neefjes, J.; Sadaka, C. Front. Immunol. 2012, 3, 31.

(8) Mommen, G. P. M.; Frese, C. K.; Meiring, H. D.; van Gaans-van den Brink, J.; de Jong, A. P. J. M.; van Els, C. A. C. M.; Heck, A. J. R. Proc. Natl. Acad. Sci. U. S. A. 2014, 111 (12), 4507-4512.

(9) Frese, C. K.; Zhou, H.; Taus, T.; Altelaar, A. F. M.; Mechtler, K.; Heck, A. J. R.; Mohammed, S. J. Proteome Res. 2013, 12 (3), 1520-1525. (10) Frese, C. K.; Altelaar, a F. M.; van den Toorn, H.; Nolting, D.; Griep-Raming, J.; Heck, A. J. R.; Mohammed, S. Anal. Chem. 2012, 84 (22), 9668-9673.
(11) Halim, A.; Westerlind, U.; Pett, C.; Schorlemer, M.; Rüetschi, U.; Brinkmalm, G.; Sihlbom, C.; Lengqvist, J.; Larson, G.; Nilsson, J. J. Proteome Res. 2014, 13 (12), 6024-6032.

(12) Bern, M.; Cai, Y.; Goldberg, D. Anal. Chem. 2007, 79 (4), 13931400.

(13) Wang, J.; Torii, M.; Liu, H.; Hart, G. W.; Hu, Z.-Z. BMC Bioinf. 2011, 12, 91 .

(14) Wang, Z.; Udeshi, N. D.; Slawson, C.; Compton, P. D.; Sakabe, K.; Cheung, W. D.; Shabanowitz, J.; Hunt, D. F.; Hart, G. W. Sci. Signaling 2010, 3 (104), ra2.

(15) Meuris, L.; Santens, F.; Elson, G.; Festjens, N.; Boone, M.; Dos Santos, A.; Devos, S.; Rousseau, F.; Plets, E.; Houthuys, E.; Malinge, P.; Magistrelli, G.; Cons, L.; Chatel, L.; Devreese, B.; Callewaert, N. Nat. Biotechnol. 2014, 32 (5), 485-489.

(16) Kastrup, I. B.; Stevanovic, S.; Arsequell, G.; Valencia, G.; Zeuthen, J.; Rammensee, H. G.; Elliott, T.; Haurum, J. S. Tissue Antigens 2000, 56 (2), 129-135.

(17) Gupta, R.; Brunak, S. Proceedings of Pacific Symposium Biocomputing 2002, Kauai, Hawaii, January 3-7, 2002; World Scientific: London, 2002; pp 310-322.

(18) Rigbolt, K. T. G.; Prokhorova, T. A.; Akimov, V.; Henningsen, J.; Johansen, P. T.; Kratchmarova, I.; Kassem, M.; Mann, M.; Olsen, J. V.; Blagoev, B. Sci. Signaling 2011, 4 (164), rs3.

(19) Hart, G. W.; Slawson, C.; Ramirez-Correa, G.; Lagerlof, O. Annu. Rev. Biochem. 2011, 80, 825-858.

(20) Lazarus, M. B.; Jiang, J.; Kapuria, V.; Bhuiyan, T.; Janetzko, J.; Zandberg, W. F.; Vocadlo, D. J.; Herr, W.; Walker, S. Science 2013, 342 (6163), 1235-1239.

(21) Gerken, T. A.; Raman, J.; Fritz, T. A.; Jamison, O. J. Biol. Chem. 2006, 281 (43), 32403-32416.

(22) Brennan, R. M.; Petersen, J.; Neller, M. A.; Miles, J. J.; Burrows, J. M.; Smith, C.; McCluskey, J.; Khanna, R.; Rossjohn, J.; Burrows, S. R. J. Immunol. 2012, 188 (6), 2742-2748.

(23) Dominguez, C.; Boelens, R.; Bonvin, A. M. J. J. J. Am. Chem. Soc. 2003, 125 (7), 1731-1737.

(24) Wolfert, M. A.; Boons, G.-J. Nat. Chem. Biol. 2013, 9 (12), 776784.

(25) Roulois, D.; Grégoire, M.; Fonteneau, J.-F. BioMed Res. Int. 2013, 2013, 871936.

(26) Vlad, A. M.; Muller, S.; Cudic, M.; Paulsen, H.; Otvos, L.; Hanisch, F.-G.; Finn, O. J. J. Exp. Med. 2002, 196 (11), 1435-1446.

(27) Grommé, M.; Uytdehaag, F. G.; Janssen, H.; Calafat, J.; van Binnendijk, R. S.; Kenter, M. J.; Tulp, A.; Verwoerd, D.; Neefjes, J. Proc. Natl. Acad. Sci. U. S. A. 1999, 96 (18), 10326-10331.

(28) Skipper, J. C.; Hendrickson, R. C.; Gulden, P. H.; Brichard, V.; Van Pel, A.; Chen, Y.; Shabanowitz, J.; Wolfel, T.; Slingluff, C. L.; Boon, T.; Hunt, D. F.; Engelhard, V. H. J. Exp. Med. 1996, 183, 527-534.

(29) Dengjel, J.; Schoor, O.; Fischer, R.; Reich, M.; Kraus, M.; Müller, M.; Kreymborg, K.; Altenberend, F.; Brandenburg, J.; Kalbacher, H.; Brock, R.; Driessen, C.; Rammensee, H.-G.; Stevanovic, S. Proc. Natl. Acad. Sci. U. S. A. 2005, 102 (22), 7922-7927.

(30) Abdel-Motal, U. M.; Berg, L.; Rosén, A.; Bengtsson, M.; Thorpe, C. J.; Kihlberg, J.; Dahmén, J.; Magnusson, G.; Karlsson, K. A.; Jondal, M. Eur. J. Immunol. 1996, 26 (3), 544-551.

(31) Tynan, F. E.; Burrows, S. R.; Buckle, A. M.; Clements, C. S.; Borg, N. A.; Miles, J. J.; Beddoe, T.; Whisstock, J. C.; Wilce, M. C.; Silins, S. L.; Burrows, J. M.; Kjer-Nielsen, L.; Kostenko, L.; Purcell, A. W.; McCluskey, J.; Rossjohn, J. Nat. Immunol. 2005, 6 (11), 1114-1122.

(32) Tynan, F. E.; Borg, N. A.; Miles, J. J.; Beddoe, T.; El-Hassen, D.; Silins, S. L.; van Zuylen, W. J. M.; Purcell, A. W.; Kjer-Nielsen, L.; McCluskey, J.; Burrows, S. R.; Rossjohn, J. J. Biol. Chem. 2005, 280 (25), 23900-23909.

(33) Ebert, L. M.; Liu, Y. C.; Clements, C. S.; Robson, N. C.; Jackson, H. M.; Markby, J. L.; Dimopoulos, N.; Tan, B. S.; Luescher, I. F.; Davis, I. D.; Rossjohn, J.; Cebon, J.; Purcell, A. W.; Chen, W. Cancer Res. 2009, 69 (3), 1046-1054.

(34) Slawson, C.; Copeland, R. J.; Hart, G. W. Trends Biochem. Sci. 2010, 35 (10), 547-555. 